\title{
Levensbeschouwing: dé basis voor burgerschapsvorming!
}

\author{
Eline Bakker a Angelique Heijstek-Hofman
}

\section{Summary}

Every child in The Netherlands is entitled to a form of decent citizenship education. At the moment, citizenship education is not given in a goal oriented and coherent way at schools in The Netherlands. Especially since education can be seen as the place in particular where students can learn how to fully participate in a democratic society in coherence with their own personal identity. This article will argue that good citizenship education requires a maximum interpretation of citizenship education and that worldview education needs to be taken as the starting point for this complete form of citizenship education. Good education has three functions: qualification, socialization, and subjectification. Citizenship education consists out of three concepts: democracy, participation and identity. These functions and domains of citizenship education overlap with worldview education. Precisely from a personal worldview a person can determine how he or she wants to participate in the democratic society. Worldview education is therefore an essential part of citizenship education.

\section{Inleiding}

Het burgerschapsonderwijs in Nederland stagneert. De sociale binding in de samenleving neemt af, burgers maken zich zorgen om het gebrek aan respect en gedeelde normen en waarden, en ook de kennis, attitudes en vaardigheden van leerlingen wat betreft burgerschapsvorming blijven achter vergeleken met

* Eline Bakker is adviseur identiteit, levensbeschouwing en burgerschapsvorming bij VOS/ABB (delandelijke vereniging voor openbaar en algemeen toegankelijk onderwijs). Tijdens de master Religie en Samenleving (Universiteit Utrecht) deed zij onderzoek naar de overlap tussen levensbeschouwelijke vorming en burgerschapsvorming en hoe deze vormingsgebieden de actief-pluriforme identiteit van het openbaar onderwijs kunnen versterken. Bakker is daarnaast één dag in de week basisschoolleerkracht op een openbare school te Amsterdam.

Angelique Heijstek-Hofman doet een PhD aan de Tilburg School of Catholic Theology van de Universiteit Tilburg. Haar onderzoek richt zich op levensbeschouwelijk onderwijs op openbare middelbare scholen. Ze heeft een BA Hebreeuwse en Joodse Studies, MA Religious Studies (beide Universiteit Leiden) en een MA Religie en Beleid (Radboud Universiteit Nijmegen) afgerond. 
leeftijdgenoten van andere vergelijkbare landen (ICCS 2016; Inspectie van het Onderwijs 2017; Ministerie van OCW 2018). De huidige burgerschapswet, die dateert van 2006, heeft een weinig verplichtend karakter: de Inspectie van het Onderwijs kan alleen ingrijpen als een school expliciet ingaat tegen de burgerschapsopdracht, de waarden van de democratische staat of als de school aan geen enkele vorm van burgerschap doet, maar zij kan geen commentaar geven op de kwaliteit van burgerschapsonderwijs.

Wij stellen in dit artikel dat alle kinderen in Nederland goed burgerschapsonderwijs verdienen en dat 'goed burgerschapsonderwijs' een maximale invulling van burgerschapsvorming vereist. Hiervoor zullen wij eerst kort een situatieschets geven van de huidige burgerschapsopdracht en het burgerschapsonderwijs in Nederland. Daaropvolgend zal worden besproken welke opvattingen er bestaan over burgerschapsonderwijs. Dit gebruiken wij als basis om onze eigen visie op burgerschapsvorming te onderbouwen, namelijk dat levensbeschouwelijke vorming een essentieel inhoudelijk onderdeel is van een maximale invulling van burgerschapsonderwijs. Tot slot doen wij een aantal aanbevelingen voor het op een maximale wijze invullen van burgerschapsvorming.

\section{De burgerschapsopdracht}

Het onderwijs is de plek waar ieder individu in onze democratische samenleving de mogelijkheid wordt geboden zichzelf op verschillende manieren te ontwikkelen. Van kennisuitbreiding tot het versterken van vaardigheden en attitudes en van het communiceren en samenwerken met andere individuen tot het ontwikkelen van een 'moreel kompas'. Het onderwijs is, idealiter, de ontmoetingsplaats bij uitstek en zou kunnen worden gezien als de plek waar kinderen leren hoe zij als volwaardige burgers kunnen leven in onze democratische samenleving. De plek waar kinderen een rijk 'palet' aangereikt kunnen krijgen dat hen handvatten biedt bij het ontwikkelen van een weldoordachte en kritische kijk op zichzelf en de wereld om hen heen. De plek waar verbinding tussen verschillende bevolkingsgroepen kan ontstaan. De plek ook waar nieuwe gedeelde waarden kunnen ontstaan. Het is echter de vraag of het Nederlandse onderwijs dit potentieel optimaal benut. De pluriforme westerse samenleving en maatschappelijke problematieken, zoals toenemend wij-zij-denken en opkomst van rechts-extremisme, stellen actuele discussies over 'goed onderwijs' (waartoe dient ons onderwijs?) en de vormende kant van het onderwijs op scherp. De versterking van burgerschapsvorming binnen 
het funderend onderwijs is, hiermee samenhangend, een actueel thema binnen debatten over het Nederlandse onderwijs. ${ }^{1}$

Het lukt Nederlandse scholen namelijk nog niet goed om op doelgerichte en samenhangende wijze aan hun (sinds 2006 wettelijk vastgelegde) burgerschapsopdracht (Ministerie van OCW 2005), die aanspoort tot het 'bevorderen van actief burgerschap en sociale integratie', te voldoen. Uit het onderzoeksrapport 'Burgerschap op school' van de Onderwijsinspectie blijkt namelijk dat, ten aanzien van burgerschapsvorming in het funderend onderwijs: de activiteiten vaak te weinig verband tonen; er dikwijls geen planmatige aanpak is; scholen vaak niet formuleren wat ze leerlingen willen leren; en scholen maar weinig zicht hebben op wat leerlingen leren (Inspectie van het Onderwijs 2017). Hiermee is het erg afhankelijk van de school en de individuele leraar op welke wijze er vorm en inhoud wordt gegeven aan het burgerschapsonderwijs. De huidige burgerschapsopdracht lijkt dus te weinig richting te geven aan scholen.

Ook uit de International Civic a Citizenship Education Study (ICCS 2016), het internationale onderzoek naar burgerschap onder leerlingen in het voortgezet onderwijs ${ }^{2}$, is gebleken dat het burgerschapsonderwijs in Nederland aan versterking toe is. Geconstateerd wordt dat Nederlandse jongeren minder weten over democratie dan leeftijdsgenoten in vergelijkbare landen, dat Nederlandse scholen weinig aan burgerschap doen en dat een relatief laag percentage Nederlandse leraren zich bekwaam voelt om les te geven over verkiezingen of de grondwet. Kortom: de Nederlandse uitkomsten van het ICCS-onderzoek 'onderstrepen' de door de Onderwijsinspectie aangehaalde urgentie van verdere versteviging van burgerschapsvorming in het funderend onderwijs (Inspectie van het Onderwijs 2017).

De stagnatie van het Nederlandse burgerschapsonderwijs heeft onze bewindslieden niet onberoerd gelaten: de burgerschapsopdracht voor het funderend onderwijs moet worden versterkt en verduidelijkt. De huidige minister voor Basis- en Voortgezet Onderwijs en Media, Arie Slob, heeft om deze redenen een wetsvoorstel geformuleerd waarbij het burgerschapsonderwijs voortaan in ieder geval moet gaan om de ontwikkeling van respect voor en kennis van de basiswaarden van de democratische rechtsstaat en de mensenrechten en om het bijbrengen van sociale en maatschappelijke competenties die leerlingen in staat stellen om deel uit te maken van en bij te dragen aan de samenleving. ${ }^{3}$ Een groot verschil met de huidige burgerschapswet is dat scholen het burgerschapsonderwijs nu op doelgerichte en samenhangende wijze moeten gaan vormgeven. De nieuwe burgerschapswet, die hoogstwaarschijnlijk in 2020 van kracht zal worden, moet scholen meer 
richting geven bij het vormgeven van hun burgerschapsonderwijs terwijl zij nog steeds ruimte hebben voor eigen invulling, aansluitend op de identiteit van de school.

Niet alleen wil de overheid scholen meer richting geven, ze wil scholen ook meer handvatten bieden om deze burgerschapsopdracht uit te voeren. De overheid is van mening dat de huidige kerndoelen van het primair en voortgezet onderwijs geactualiseerd moeten worden. Deze 'herijking' wordt uitgevoegd door middel van een curriculumherziening, genaamd Curriculum. $\mathrm{nu}$ (voorheen 'Platform2032'). Binnen Curriculum.nu zijn er ontwikkelteams aan de slag die op verschillende domeinen visie en bouwstenen ontwikkelen voor het onderwijs van de toekomst - zo ook voor burgerschap. Hoewel de curriculumherziening op het moment van schrijven nog bezig is, blijkt uit de voorlopige visie die het ontwikkelteam Burgerschap heeft geformuleerd dat het de inhoudelijke kern van burgerschapsonderwijs zoals de Onderwijsraad deze verwoordt, heeft overgenomen. Onder burgerschapsonderwijs wordt volgens Curriculum.nu namelijk verstaan dat 'jongeren leren functioneren, vanuit eigen idealen, waarden en normen, in een pluriforme, democratische samenleving, en bij hen het vermogen ontwikkelen om aan deze samenleving een bijdrage te willen leveren' (Onderwijsraad 2012, 14; Curriculum.nu 2018, 1).

De inhoudelijke kern die Curriculum.nu heeft overgenomen van de Onderwijsraad bevat, globaal gezien, twee belangrijke componenten, namelijk ten eerste de kennis over de democratische rechtstaat en de waarden en spelregels die daaraan ten grondslag liggen en ten tweede de identiteitsontwikkeling van leerlingen, dat wil zeggen de ontwikkeling van en de reflectie op eigen idealen, normen en waarden en de eigen positie in de samenleving (Onderwijsraad 2012). Bovenstaande ontwikkelingen kunnen voor scholen het momentum betekenen om een doelgerichte(re) visie en samenhangende(r) aanpak op het (burgerschaps)vormingsonderwijs op hun scholen te ontwikkelen - en het liefste natuurlijk vanuit een maximale invulling van burgerschapsvorming, waarbij naast aandacht voor democratie ook identiteitsontwikkeling een fundamentele plek heeft.

\section{Burgerschapsvorming - wat verstaan we er eigenlijk onder?}

Het aanleren van een democratische houding en de identiteitsontwikkeling van leerlingen zijn belangrijke pijlers voor burgerschapsvorming; dit wordt ook onderstreept door de SLO (2009), het nationale expertisecentrum voor curriculumontwikkeling. De SLO onderscheidt drie domeinen binnen 
burgerschapsvorming: democratie, participatie en identiteit. De verschillende domeinen kunnen zowel samen als los van elkaar werken en beïnvloeden elkaar altijd binnen onderwijsleerprocessen. Binnen het domein identiteit gaat het niet alleen om de persoonlijke vorming van een leerling maar ook om het omgaan en het waarderen van diversiteit, bijdragen aan sociale integratie en het leren van een democratische houding. Deze 'democratische houding' waar de SLO van spreekt, is gebaseerd op het idee van John Dewey (1916) die stelt dat democratie niet alleen gezien kan worden als een regeringsvorm, maar voornamelijk een vorm is van samenleven, oftewel democracy as a way of life. Volgens hem is de school een 'samenleving in het klein', waar kinderen leren hoe als volwaardige burgers te leven in de maatschappij en burgerschap oefenen door middel van actieve participatie. Dit laat zien dat democratie, (actieve) participatie en identiteitsontwikkeling, de drie pijlers van SLO, intrinsiek met elkaar verweven zijn.

Desondanks is het verwerven van kennis, vaardigheden en competenties op dit moment nog steeds de meest kenmerkende functie van het huidige onderwijs (de zogeheten 'toetscultuur'). Gert Biesta (2012) noemt dit onderwijsdoeldomein (of onderwijsfunctie) kwalificatie. Maar naast kwalificatie wordt de zin en richting van 'goed' onderwijs ook bepaald door twee andere domeinen, namelijk socialisatie en subjectificatie. Hiermee zegt hij dat onderwijs naast het doorgeven van kennis en het aanleren van vaardigheden ook aandacht moet schenken aan de vraag hoe de leerlingen een onderdeel kunnen zijn en zich onderdeel kunnen voelen van een culturele of sociale gemeenschap, zodat ze niet alleen actief kunnen participeren maar ook intrinsiek sociaal betrokken willen zijn bij de samenleving (socialisatie). In het laatste domein, subjectificatie - ook wel persoonlijke vorming of persoonsvorming genoemd -, staat de identiteitsontwikkeling van de leerling centraal. Dit domein heeft tot doel dat leerlingen leren hoe ze in hun denken en handelen onafhankelijk kunnen zijn van de eigen omgeving waardoor zij zich bewust worden van hun eigen identiteit, hun eigen mening en de uniciteit daarvan. Het ontdekken van persoonlijke waarden en drijfveren staat centraal binnen persoonsvorming.

Subjectificatie als domein binnen burgerschapsvorming betekent niet alleen dat aandacht moet worden gegeven aan hoe leerlingen als persoon willen zijn en waarom, maar ook aan hoe zij zich verhouden tot anderen en de samenleving. Dit maakt actief deelnemen aan de eigen omgeving en de samenleving, dus participatie, een even essentieel onderdeel van burgerschapsvorming als democratie en identiteit.

Kritisch en onafhankelijk nadenken, sociaal betrokken zijn bij de samenleving, omgaan met en het waarderen van de pluriforme samenleving, actieve 
participatie in dialogen en zelfontplooiing zijn aspecten die behoren tot het kritisch-democratisch burgerschap. Dit is een van drie typen burgerschap die Wiel Veugelers (2017) onderscheidt naast aanpassingsgericht (waarbij de nadruk ligt op het aanpassen van een persoon aan de gemeenschap) en individualistisch burgerschap (waarvoor geldt dat er meer belang wordt gehecht aan de autonomie van een persoon dan aan de gemeenschappelijke belangen). Deze typeringen kunnen worden gezien als verschillende oriëntaties op burgerschap die mogelijk zijn, en hoewel deze typen niet staan voor goede of slechte vormen van burgerschap, wordt het kritisch-democratisch burgerschap gezien als het ideale type. Kritisch-democratisch burgerschap legt namelijk de nadruk op kritische en democratische betrokkenheid bij de gemeenschap, waarbij het ruimte laat voor de autonome ontwikkeling van een persoon (Veugelers 2017). Ook dit type burgerschap laat zien dat democratie, de ontwikkeling van een persoonlijke identiteit en willen participeren in de maatschappij onlosmakelijk met elkaar verbonden zijn. De verbondenheid van deze concepten zorgt, volgens ons, voor een sterke en complete vorm van burgerschap.

Op basis van verschillende opvattingen hebben wij in deze paragraaf willen aantonen dat burgerschapsonderwijs bestaat uit drie verschillende inhoudelijke concepten, namelijk identiteit, participatie en democratie. Daarnaast heeft goed onderwijs drie functies of doeldomeinen: kwalificatie, socialisatie en subjectificatie (of persoonsvorming). Aan de hand van het op elkaar betrekken van bovenstaande inhoudelijke onderwijsconcepten en onderwijsdomeinen concluderen wij in de volgende paragraaf dat levensbeschouwelijke vorming een onmisbaar onderdeel is binnen een compleet burgerschapscurriculum.

\section{Compleet burgerschapscurriculum? Levensbeschouwelijke vorming!}

Bovenstaande theorieën en concepten brengen ons tot de conclusie dat het vormen van een weldoordachte visie op de eigen identiteit en de wereld om je heen als essentieel en zelfs onmisbaar onderdeel van burgerschapsvorming kan worden beschouwd. Oftewel: levensbeschouwelijke vorming is een onmisbaar onderdeel van een compleet burgerschapscurriculum. In deze opvatting staan wij niet alleen. De theorie van Siebren Miedema over 'levensbeschouwelijke burgerschapsvorming' sluit naadloos aan bij deze aanname en daarom zullen we zijn theorie hieronder kort belichten. 
Al sinds 2000 voert Siebren Miedema een nationaal en internationaal pleidooi om levensbeschouwelijke vorming te verbinden aan burgerschapsvorming, onder de noemer 'levensbeschouwelijke burgerschapsvorming'. Daarnaast pleit hij voor levensbeschouwelijke vorming voor alle leerlingen op alle scholen. Volgens Miedema behoort levensbeschouwelijke vorming tot een volledig burgerschapscurriculum (Miedema, Bertram-Troost \& Veugelers 2013). In 2011 publiceerden Miedema en Ina ter Avest het artikel In the flow to maximal interreligious citizenship education, waarin zij pleiten voor een maximale invulling van burgerschapsvorming, interreligieus onderwijs en waarin zij stellen dat de levensbeschouwelijke identiteit een integraal deel is van het concept 'persoonlijke identiteitsontwikkeling'. Het ontwikkelen van een persoonlijke identiteit is namelijk niet mogelijk zonder het ontwikkelen van eigen normen en waarden, idealen en een visie op het leven en (hoe bij te dragen aan) de wereld (Miedema \& Ter Avest 2011).

Wij onderstrepen deze visie in hoge mate en willen deze opvatting onderbouwen door dieper in te gaan op de definitie en inhouden van levensbeschouwelijke vorming. De term 'levensbeschouwing' is immers een ambigu begrip dat aan veel betekenissen onderhevig is. Wij gaan uit van de definitie zoals geformuleerd door Van den Berg, Ter Avest en Kopmels (2013, 21), namelijk: 'levensbeschouwing is een samenhangend geheel van ideeën, ervaringen, waarden en beelden dat een persoon ontwikkelt over zichzelf, over het samenleven met anderen en over de wereld.' Oftewel: 'het leven beschouwen' is iets dat $e l k$ persoon in meer of mindere mate doet en de levensbeschouwing van een persoon kan beïnvloed worden door een religie of door een seculiere levensbeschouwing zoals het humanisme. Hoewel niet altijd bewust, begint het beschouwen van het leven al van kinds af aan. Levensbeschouwing is een integraal deel van de persoonlijke identiteitsontwikkeling van ieder kind en is onlosmakelijk verbonden met het ontwikkelen van een visie op het samenleven met anderen en op de wereld.

Belangrijke aspecten die binnen levensbeschouwelijke vorming, naar onze mening en aansluitend op bovenstaand verhaal, in ieder geval een vaste plek zouden moeten hebben, zijn: ontwikkeling van en reflectie op de eigen identiteit ('Wie ben ik?', 'Waar sta ik voor?', 'Waar ben ik goed in?', 'Wie wil ik worden?'), het onderzoeken van universele bestaansvragen, aandacht voor zingeving ('Waar geloof ik in?', 'Wat vind ik belangrijk in het leven?') maar ook het leren openstaan voor andere perspectieven en zich leren verhouden tot 'het andere' en de omringende wereld (zoals voor het primair onderwijs wettelijk vastgelegd is in kerndoel 38 , waarin staat dat kinderen hoofdzaken over geestelijke stromingen leren die in onze multiculturele samenleving een 
belangrijke rol spelen én respectvol leren om te gaan met verschillende opvattingen van mensen). Maar ook zouden kinderen moeten worden uitgedaagd om vanuit een kritisch-democratische en reflectieve houding een visie te vormen op de vraag hoe zij vanuit hun eigen unieke identiteit willen gaan meedoen in de democratische samenleving. Het is belangrijk dat kinderen niet alleen (actief) kunnen participeren in een gemeenschap, maar ook dat zij dit willen, vanuit hun eigen identiteit en vanuit hun eigen visie op het leven en de wereld. Vanuit een persoonlijke levensbeschouwing kan een leerling bepalen hoe hij of zij wil participeren in de samenleving.

Dit laat weer de onlosmakelijke verbondenheid tussen levensbeschouwelijke vorming en burgerschapsvorming zien. Op een systematische manier aandacht geven aan de levensbeschouwelijke en persoonlijke ontwikkeling van kinderen draagt in hoge mate bij aan het op een maximale wijze invulling geven aan de burgerschapsopdracht. Ook als we de verschillende initiatieven van de overheid en het theoretisch kader met elkaar verbinden, constateren wij dat levensbeschouwelijke vorming (waarbij wij de definitie hanteren zoals hierboven genoemd) een essentieel onderdeel is van burgerschapsvorming. Bovenstaande mogelijke inhouden van levensbeschouwelijke vorming (en dus eigenlijk ook van burgerschapsvorming) doen recht aan Biesta's onderwijsdoeldomeinen socialisatie en persoonsvorming - de onderwijsdomeinen die op moment van schrijven nog te vaak overschaduwd worden door de kwalificatiefunctie van het onderwijs.

Hoe op een complete of 'maximale' manier invulling te geven aan de burgerschapsopdracht is hierboven besproken: goed en volledig burgerschapsonderwijs is gestoeld op de drie functies en doeldomeinen van onderwijs die Biesta onderscheidt, namelijk kwalificatie, socialisatie en persoonsvorming, en gaat om drie basisconcepten: democratie, participatie en identiteit. Wij willen hiermee de overlap aantonen tussen de verschillende inhoudelijke concepten van burgerschapsvorming en levensbeschouwelijke vorming en de functies van goed onderwijs. Door levensbeschouwelijke vorming onderdeel te maken van burgerschapsvorming wordt er op een persoonsgerichte manier aandacht gegeven aan burgerschap. Wij pleiten er dan ook voor om structurele aandacht te geven aan levensbeschouwelijke vorming op alle scholen - zowel in het openbaar als in het bijzonder onderwijs. Levensbeschouwing hoeft hierbij niet per definitie een apart vak te zijn, het kan ook geïntegreerd worden in vakgebieden zoals Mens en Maatschappij of het kan op systematische en concrete wijze onderdeel zijn binnen andere vakgebieden. 


\section{Naar een maximale invulling van burgerschapsvorming}

Het op een maximale wijze invulling geven aan burgerschap is iets dat raakt aan het fundament van de school: de identiteit van de school, de waarden waar de school voor staat. Het wetsvoorstel Verduidelijking burgerschapsopdracht in het funderend onderwijs (2018), waarin naar voren komt dat scholen op een doelgerichte en samenhangende wijze invulling moeten geven aan burgerschapsvorming maar waarbij er ruimte blijft voor de eigen identiteit van de school, kan als 'trigger' worden gezien om het onderwijs (en naast de kwalificerende juist ook de socialiserende en subjectiverende pijlers) weer eens kritisch onder de loep te nemen. Wij stellen levensbeschouwelijke vorming als onderdeel van goed burgerschapsonderwijs centraal, omdat op die manier aandacht kan worden gegeven aan de drie functies van goed onderwijs: kwalificatie, socialisatie en persoonsvorming.

Naast Biesta en Curriculum.nu die persoonsvorming als doel centraal stellen en die prioriteit geven aan identiteit als onderdeel van de burgerschapsopdracht, komt er ook vanuit een andere hoek een roep om concretere en systematische aandacht voor de levensbeschouwelijke vorming van leerlingen. Het recent opgerichte expertisecentrum Levensbeschouwing en Religie in het Voortgezet Onderwijs (LERVO) onderschrijft het belang van levensbeschouwelijke en burgerschapsvorming als voorbereiding op het functioneren in de pluriforme samenleving. Dit expertisecentrum betoogt dat iedere leerling recht heeft op goede levensbeschouwelijke educatie in het voortgezet onderwijs. ${ }^{4}$ De inrichting van dit levensbeschouwelijk onderwijs kan op verschillende manieren worden ingevuld, ook als onderdeel van burgerschapsvorming, zodat er rekening kan worden gehouden met de bestaande en diverse onderwijspraktijk (Visser et al 2018).

De school is een samenleving in het klein waar kinderen kunnen oefenen met het aannemen van een democratische houding, eigen waarden en visie op het leven leren ontwikkelen, leren hoe zich in te leven in anderen en hoe om te gaan met diversiteit. Waar kinderen leren hoe zij hun steentje zouden willen bijdragen aan de samenleving, aansluitend op hun eigen identiteit. Het lijkt ons daarom van belang dat de context waarin dit oefenen gebeurt, zoveel mogelijk een afspiegeling is van de pluriforme Nederlandse samenleving, waar leerlingen met verschillende culturele, sociaal-economische of levensbeschouwelijke achtergronden elkaar kunnen ontmoeten en leren begrijpen. Burgerschapsonderwijs maximaal invullen zou ook moeten inhouden dat het terugkomt in de cultuur en het pedagogisch klimaat van de school en in de relatie tussen de school en de omgeving (participatie). Denk hierbij aan 
(duurzame) samenwerkingsprojecten in de omgeving van de school, zoals een samenwerking met het bejaardenhuis of andere 'stakeholders' uit de buurt van de school.

Het openbaar onderwijs lijkt ons bij uitstek de plek waar een maximale invulling kan worden gegeven aan burgerschap, zowel inhoudelijk, organisatorisch én contextueel. Openbare scholen zijn scholen van én voor de samenleving en staan open voor iedereen, waarbij culturele, levensbeschouwelijke en seksuele diversiteit wordt gewaardeerd. Door de ontmoeting met andersdenkenden leren kinderen van elkaar, en dit kan het onderling begrip bevorderen. Dit is ook precies wat behoort tot de opdracht van het openbaar onderwijs, namelijk de opdracht tot actieve pluriformiteit. In artikel 42 van de Wet op het voortgezet onderwijs wordt deze opdracht beschreven: openbare scholen dienen bij te dragen 'aan de ontwikkeling van de leerlingen met aandacht voor de godsdienstige, levensbeschouwelijke en maatschappelijke waarden zoals die leven in de Nederlandse samenleving, en met onderkenning van de betekenis van de verscheidenheid van die waarden'. Juist op een systematische en concrete manier aandacht geven aan levensbeschouwelijke vorming kan een eerste stap zijn naar het versterken van het burgerschapsonderwijs als onderdeel van de actief-pluriforme opdracht voor het openbaar onderwijs.

Om op maximale wijze invulling te geven aan burgerschapsonderwijs (dus met aandacht voor kwalificatie, socialisatie en persoonsvorming en identiteit, participatie en democratie en met structurele aandacht voor levensbeschouwelijke vorming), stellen wij voor om per school een burgerschapscoördinator aan te stellen die zich kan verdiepen in theorieën over 'goed onderwijs', theorieën over burgerschapsvorming, levensbeschouwelijke vorming en identiteitsontwikkeling, de nieuwe burgerschapswet die medio 2020 in zal gaan, de integratie tussen verschillende vak- en vormingsgebieden, de inhouden van curriculum.nu en uiteraard de context, visie en praktijken van de school. Hoe wordt er vorm en inhoud gegeven aan deze vormingsgebieden? Vaak gebeuren er al veel dingen op een school die raken aan levensbeschouwelijke vorming en burgerschapsvorming en aan de waarden waar de school voor staat. De burgerschapscoördinator zou op doelgerichte en samenhangende wijze in kaart kunnen brengen wat er al gebeurt op de school, en daarop aansluitend welke aspecten versterkt zouden moeten worden om tot concrete en samenhangende leerlijnen te komen die aansluiten bij de visie van de school. Bij het vormen van een heldere visie op bovenstaande punten is het van belang dat docententeams de dialoog aan gaan met elkaar over de identiteit en pedagogische visie van de school en daarop aansluitend de koers die zij willen 
varen ten aanzien van burgerschap en de levensbeschouwelijke identiteitsontwikkeling van de kinderen. Zo wordt recht gedaan aan de onderwijsfuncties en -doeldomeinen kwalificatie, socialisatie en persoonsvorming. Óp naar een rijkere invulling van burgerschapsvorming voor ieder kind, door de levensbeschouwelijke identiteitsontwikkeling als startpunt te nemen!

\section{Noten}

1 Met het funderend onderwijs wordt het primair onderwijs en de onderbouw van het secundair onderwijs bedoeld.

2 De International Civic \& Citizenship Education Study is in 24 landen uitgevoerd. In Nederland is dit onderzoek uitgevoerd door de Universiteit van Amsterdam en het Kohnstamm Instituut. Het onderzoek is gefinancierd door het Nationaal Regieorgaan Onderwijsonderzoek en het Ministerie van Onderwijs, Cultuur \& Wetenschap.

3 Het hier beschreven wetsvoorstel, genaamd Verduidelijking burgerschapsopdracht in het funderend onderwijs is begin juni 2018 gepubliceerd.

4 In het primair onderwijs moeten alle scholen aandacht geven aan geestelijke stromingen en op openbare basisscholen kan er godsdienst of humanistisch vormingsonderwijs worden aangeboden.

5 Dezelfde wet geldt ook voor het primair onderwijs, zie artikel 46 van de Wet op het primair onderwijs.

\section{Literatuur}

Berg, B. van den, I. ter Avest \& T. Kopmels, (2013),

Geloof je het zelf?! Levensbeschouwelijk leren in het basisonderwijs, Bussum: Coutinho.

Biesta, G. (2012),

Goed onderwijs en de cultuur van het meten. Ethiek, politiek en democratie, Den Haag:

Boom Lemma uitgevers.

Bron, J., W. Veugelers \& E. van Vliet (2009),

Leerplanverkenning actief burgerschap. Handreiking voor schoolontwikkeling, Enschede: SLO.

Curriculum.nu (2018),

Visie op het leergebied Burgerschap, (Curriculum.nu, december 2018).

Dewey, J. (1916),

Democracy and Education. An introduction to the philosophy of education, New York: Macmillan.

Inspectie van het Onderwijs (2017),

Burgerschap op school. Een beschrijving van burgerschapsonderwijs en de maatschappelijke stage, Utrecht: Inspectie van het Onderwijs. 
International Civics and Citizenship Education Study (2016), International Civics and Citizenship Education study 2016 Nederland, (ICCS/IEA).

Miedema, S. \& I. ter Avest (2011),

In the Flow to Maximal Interreligious Citizenship Education, in: Religious Education, 106 (4), 410-424.

Miedema, S., G. Bertram-Troost \& W. Veugelers (2013), Onderwijs, Levensbeschouwing en het Publiek Domein. Inleiding op het Themanummer, in: Pedagogiek, 33 (2), 73-89.

Ministerie van Onderwijs, Cultuur en Wetenschap (2005),

Wetsvoorstel 29959 'Bevordering actief burgerschap en sociale integratie', Den Haag: OCW.

Ministerie van Onderwijs, Cultuur en Wetenschap (2018), Verduidelijking burgerschapsopdracht in het funderend onderwijs, Den Haag: OCW.

Onderwijs (2012),

Verder met burgerschap in het onderwijs, Den Haag: Onderwijsraad.

Veugelers, W. (2017),

Education for Critical-Democratic Citizenship. Autonomy and Social Justice in a Multicultural Society, in: Aloni, N. \& L. Weintrob (eds.), Beyond Bystanders. Educational Leadership for a Humane Culture in a Globalizing Reality, Rotterdam: SensePublishers, 47-59.

Veugelers, W. \& E. Oostdijk (2013),

Humanistische Levensbeschouwelijke Vorming. Levensbeschouwelijke vorming in het Nederlands onderwijs, in het bijzonder HVO, in: Pedagogiek, 33 (2), 136-152.

Visser, T., J.M. Praamsma, M. van Dijk-Groeneboer, M.A. Davidsen \& T. de Beer (2018), Het vakgebied levensbeschouwing en religie in het voortgezet onderwijs, in: Narthex, 18 (4), (26-37) 